\title{
Analisis Kualitas Pelayanan Pada Universitas Lancang Kuning
}

\author{
JENI WARDI ${ }^{1}$, LIVIAWATI $^{2}$, GUSMARILA EKA PUTRI $^{3}$ \\ ${ }^{1,2,3}$ Universitas Manakarya Utama \\ Jln. Yos Sudarso KM 08 Rumbai Telp. (0761) 52581 \\ E-mail : gusmarilaekaputri@unilak.ac.id
}

\begin{abstract}
Having a vision for Unilak leading 2030 by becoming a leading university on national level based on Malay culture requires cooperation from all parties to make it happen. The points to be achieved one of them is to improve the quality of education. High quality education will not be achieved if it is not concerned with student satisfaction as a college customer and will become a threat when competition is increasingly tight for colleagues if not pay attention to student satisfaction. The purpose of this research is to measure and analyze service quality of 3 Faculties at UNILAK (FIA, FKIP \& FH) seen from student satisfaction in five dimension SEVQUAL (tangible, reliability, responsives, assurance, and empathy). The method used is a case study in Unilak environment with questionnaire distribution techniques to FIA, FKIP \& FH students. Data analysis technique use linear regression method with SPSS application.
\end{abstract}

Keywords: Service Quality, Student Satisfaction

Universitas Lancang Kuning (Unilak) didirikan dengan tujuan utama untuk membantu siswa-siswa yang saat itu tidak mampu dari segi biaya yang cukup untuk melanjutkan studi atau mendapatkan pendidikan yang berkualitas di tingkat perguruan tinggi. Dalam perjalananya selama 35 tahun sejak didirikan, Unilak telah menghasilkan puluhan ribu alumni dari 9 fakultas, 21 program studi dan 2 program pascasarjananya.

$$
\text { Sebagai Universitas yang }
$$
diharapkan mampu berperan secara strategis sebagai penyedia sumber daya manusia unggul. Unilak Pekanbaru sesuai tagline nya yakni "Universitas Kebanggaan Masyarakat Riau" menghadapi persaingan yang semakin global dengan adanya MEA. Oleh karena itu Unilak Pekanbaru haruslah didukung oleh banyak elemen salah satunya adalah pelayanan prima.

$$
\text { Unilak sebagai universitas }
$$

kebanggaan masyarakat Riau tentulah harus memiliki kualitas pelayanan yang prima. Menyusun, menetapkan, dan menerapkan standar pelayanan khususnya untuk masyarakat eksternal terkait apa saja yang berkaitan dengan pelayanan haruslah dicermati lebih serius oleh segenap pihak. Kepentingan umum, kepastian hukum, kesamaan hak, keseimbangan hak dan kewajiban, keprofesionalan, partisipatif, non diskriminatif, terbuka, akuntabel, dan tepat waktu dan yang terpenting dari pelayanan publik di Unilak haruslah cepat, mudah dan terjangkau agar mampu bersaing ditengah kompetisi ditingkat perguruan tinggi yang makin marak dan global.

Pelayanan yang memiliki standar prima (Service excellent) dan berorientasi kepada kepuasan pelanggan akan dapat memberi citra positif Unilak sebagai universitas yang diakui. Abdullah dan Tantri (2012) mengatakan kepuasan adalah tingkat perasaan seseorang setelah membandingkan kinerja produk (hasil) yang ia rasakan dengan harapannya. Jadi tingkat kepuasan merupakan fungsi dari perbedaan antara kinerja yang dirasakan dan harapannya. Pelanggan di Unilak dapat diartikan mahasiswa, dosen maupun masyarakat umum bisa mengalami salah satu dari tiga tingkat kepuasan yang umum. Jika kinerja dibawah harapan, pelanggan akan puas. Apabila kinerja 
melampaui harapan, pelanggan akan sangat puas, senang, atau bahagia. Oleh karena itu pengukuran terhadap hal tersebut sangat penting untuk dilakukan agar Unilak masyarakat Riau tahu apakah Institusi yang menjadi kebanggaan mereka tersebut sudah berada pada jalur yang benar atau hanya dijalankan sekedarnya saja.

Pengukuran kualitas pelayanan pada riset eksplanatori ini mencoba menentukan kepuasan pelanggan berdasarkan 5 dimensi yakni; responsiveness, assurance, empathy, dan tangibles. Firdaus Abdullah (2011) senada dengan sejumlah besar studi empiris tentang model SERVQUAL seperti (Rodrigues, L. L., Barkur, G., Varambally, K. V. M., \& Golrooy Motlagh, F, 2011; Amiri Aghdaie, S. F., \& Faghani, F., 2012; Chingang Nde, D., \& Lukong, P. 2010). Penelitian-penelitian tersebut mengembangkan sebuah analisis faktorial menunjukkan bahwa kualitas pelayanan memiliki tiga dimensi yaitu "Systemization of service delivery", "Komunikasi Handal" dan "Responsivitas". Oleh karena itu penelitian ini dirancang untuk menguji tingkat pelayanan terhadap kepuasan mahasiswa dan untuk mengetahui apakah kualitas pelayanan berupa wujud fisik (tangibles), kehandalan (reliability), daya tanggap (responsiveness), jaminan (assurance) dan kepedulian (emphaty) berpengaruh pada kepuasan public

Pendapat Saputra, R. L. (2014) menyatakan "Pelayanan adalah suatu usaha yang dilakukan kelompok atau seseorang atau birokrasi untuk memberikan bantuan kepada masyarakat dalam rangkamencapai suatu tujuan tertentu". Sehingga berdasarkan uraian di atas dapat dikatakan pelayanan merupakan kegiatan utama pada orang yang bergerak di bidang jasa, baik itu orang yang bersifat komersial ataupun yang bersifat non komersial.

Kualitas pelayanan yang baik sering dikatakan sebagai salah satu faktor penting dalam keberhasilan suatu bisnis. Penelitian yang dilakukan oleh Kheng, L. L., Mahamad, O., Ramayah, T., \& Mosahab, R. (2010) menyatakan bahwa kualitas jasa mempunyai pengaruh yang signifikan terhadap kepuasan pelanggan. Maka, suatu perusahaan dituntut untuk memaksimalkan kualitas pelayanannya agar mampu menciptakan kepuasan para pelanggannya. Oleh karena itu pelayanan yang berkualitas dalam sebuah institusi atau perusahaan adalah kemampuan suatu institusi atau perusahaan menyajikan atau memenuhi apa yang dijanjikannya kepada pelanggan.

\subsection{Kepuasan Pelanggan (Mahasiswa)}

Kotler (2007) menyatakan bahwa kepuasan adalah perasaan senang atau kecewa seseorang yang berasal dari perbandingan kesannya terhadap kinerja atau hasil suatu produk dan harapanharapannya. Jika kinerja berada dibawah harapan, pelanggan tidak puas. Hal ini dapat membawa dampak negatif bagi perusahaan yaitu dapat menurunkan jumlah pelanggan dan menyebabkan pelanggan tidak tertarik lagi menggunakan jasa perbankan sehingga akan menurunkan laba perusahaan. Dapat ditarik kesimpulan bahwa pada dasarnya pengertian kepuasan pelanggan mencakup perbedaan antara harapan dan kinerja atau hasil yang dirasakan.

Hubungan wujud fisik (tangible) dengan kepuasan nasabah adalah: wujud fisik (tangible) mempunyai pengaruh positif dan signifikan terhadap kepuasan nasabah. Semakin baik persepsi pelanggan terhadap wujud fisik (tangible) maka kepuasan nasabah akan semakin tinggi. Dan jika persepsi nasabah terhadap wujud fisik (tangible) buruk, maka kepuasan nasabah semakin rendah.

Kehandalan adalah kemampuan untuk memberikan jasa sesuai dengan yang dijanjikan dengan akurat dan handal. Hubungan kehandalan (reliability) dengan kepuasan nasabah adalah: kehandalan (reliability) mempunyai pengaruh positif dan signifikan terhadap kepuasan nasabah. Semakin baik persepsi pelanggan terhadap kehandalan (reliability) maka kepuasan nasabah 
semakin tinggi. Jika persepsi nasabah terhadap kehandalan (reliability) buruk, maka kepuasan nasabah akan semakin rendah.

Daya tanggap adalah kesedian untuk membantu pelanggan dan memberikan dengan segera dan tepat. Ini menekankan pada perhatian dan kecepatan dalam menghadapi permintaan, pernyataan, keluhan serta kesulitan pelanggan

$$
\text { Hubungan daya tanggap }
$$

(responsiveness) dengan kepuasan nasabah adalah: daya tanggap (responsiveness) mempunyai pengaruh positif dan signifikan terhadap kepuasan nasabah. Semakin baik persepsi pelanggan terhadap daya tanggap (responsiveness) maka kepuasan mahasiswa akan semakin tinggi. Jika persepsi mahasiswa terhadap daya tanggap (responsiveness) buruk, maka kepuasan mahasiswa akan semakin rendah.

Assurance mencakup pengetahuan, kemampuan, kesopanan, sifat dapat dipercaya yang dimiliki para staf, dan bebas dari bahaya, risiko atau keraguraguan. Hubungan jaminan (assurance) dengan kepuasan mahasiswa adalah: jaminan (assurance) mempunyai pengaruh positif dan signifikan terhadap kepuasan mahasiswa. Semakin baik mahasiswa terhadap jaminan (assurance) maka kepuasan mahasiswa akan semakin tinggi. Jika persepsi mahasiswa terhadap jaminan (assurance) buruk maka kepuasan mahasiswa akan semakin rendah.

Empati adalah perhatian secara individu yang diberikan oleh penyedia jasa sehingga pelanggan merasa penting, dihargai dan dimengerti oleh perusahaan.

Dabholkar et al (2000) dalam Tciptono (2005) menyatakan bahwa kualitas jasa mempunyai pengaruh yang signifikan terhadap kepuasan pelanggan. Berdasarkan uraian di atas, maka hipotesis yang dapat diambil dalam penelitian ini adalah kualitas pelayanan mempunyai pengaruh yang positif terhadap kepuasan pelanggan.

\section{METODE}

Penelitian ini akan dilakukan pada bulan September 2017 sampai Januari 2018 di Fakultas Ilmu Administrasi, Hukum dan FKIP Universitas Lancang Kuning (Unilak). Sumber data yang digunakan dalam penelitian ini adalah data primer, yakni berupa kuesioner. Ada 30 items pertanyaan didesain untuk bisa membantu menjawab pertanyaan pada penelitian ini. Items pertanyaan yang diajukan pada responden didesain dan diolah dengan skala likert. Tindak lanjut dari pengumpulan data adalah menganalisis data untuk menganalisis data kualitatif maka digunakan analisis Regresi berganda dengan bantuan aplikasi SPSS.

\section{HASIL}

Uji validitas digunakan untuk mengukur valid atau tidaknya suatu kuesioner. Suatu kuesioner dikatakan valid jika pertanyaan pada kuesioner mampu untuk mengungkapkan suatu yang akan diukur oleh kuesioner tersebut.

Apabila skor total menghasilkan nilai signifikansi $<0,05(\alpha=5 \%)$ maka item pertanyaan dikatakan valid. Sebaliknya jika nilai signifikansi yang dihasilkan $>0,05(\alpha=5 \%)$ maka item pertanyaan dikatakan $(\alpha=5 \%)$ tidak valid atau gugur (Ghozali, $2011 ; 52$ ).

Pada hasil uji reliabilitas menunjukkan bahwa instrument penelitian mempunyai reliabilitas yang tinggi dengan nilai Cronbach's Alpha 0,930 untuk Kepuasan Mahasiswa (Y), 0,846 untuk Tangible (X1), 0,893 untuk Reliability (X2), 0,905 untuk Responsiveness (X3), 0,912 untuk Assurance (X4), dan 0,883 untuk Empathy (X5).

Hasil uji normalitas menunjukkan bahwa sebaran data adalah normal. Alat diagnosis yang digunakan dalam menguji distribusi normal data adalah histogram dan plot normal. Berdasarkan output histogram, nampak mengikuti distribusi normal dengan jumlah data 72 responden didapat mean 5,46 dan standar deviasi 0,964. Dapat disimpulkan data berdistribusi normal. 
Berdasarkan nilai variance Inflation Factor (VIF) berkisar pada nilai 1 atau lebih rendah dari 10 , nilai VIF tangible sebesar $1.515<10$, nilai VIF reliability $1.546<10$, nilai VIF responsiveness sebesar $2.201<10$, nilai VIF assurance $2.321<10$, nilai VIF empathy $1.590<10$, sehingga dapat disimpulkan tidak terdapat multikolinieritas.

Dari gambar Scatterplot tersebut terlihat titik-titik tidak membentuk pola tertentu dan menyebar secara acak diatas dan dibawah angka 0 pada sumbu Y. Dapat diartikan tidak terdapat heterokedastisitas dalam model regresi penelitian ini.

Berdasarkan persamaan regresi linier berganda yang dihasilkan adalah sebagai berikut :

$\mathrm{Y}=\mathrm{a}+\mathrm{b}_{1} \mathrm{X}_{1}+\mathrm{b}_{2} \mathrm{X}_{2}+\mathrm{b}_{3} \mathrm{X}_{3}+\mathrm{b}_{4} \mathrm{X}_{4}+\mathrm{b}_{5} \mathrm{X}_{5}+\mathrm{e}$ $\mathrm{Y}=-0.728+0.050 \mathrm{X}_{1+} 0.283 \mathrm{X}_{2}+0.177 \mathrm{X}_{3}$ $+0.300 \mathrm{X}_{4}+0.205 \mathrm{X}_{5}$

Persamaan regresi ini menjelaskan variabel yang paling mempengaruhi kepuasan mahasiswa. Variabel bebas terhadap variabel terikat dapat dilihat melalui standardized coefficents nya. Dalam penelitian ini dapat dilihat bahwa variabel yang memiliki pengaruh paling besar adalah assurance total dengan standardized coefficents yaitu 0.281 .

Pada pengujian secara simultan (Uji F) diperoleh $\mathrm{F}$ hitung sebesar 28,857 dengan signifikansi sebesar 0,000. Diperoleh F tabel sebesar 4,40. Dengan demikian dapat diketahui $\mathrm{F}$ hitung $>\mathrm{F}$ tabel dengan signifikansi $(0,000<0,05)$, artinya variabel tangible, reliability, responsiveness, assurance, dan empathy secara bersamasama berpengaruh signifikan terhadap variabel kepuasan mahasiswa.

\section{PEMBAHASAN}

Pengujian ini dilakukan untuk menguji hipotesis-hipotesis yang terdapat dalam penelitian ini $\mathrm{H}_{1}$ yang diajukan pada penelitian ini adalah:

Hasil pengujian Pengaruh Wujud Fisik (Tangible) Terhadap Persepsi Kepuasan Mahasiswa

Berdasarkan nilai $\mathrm{t}$ hitung 0,506 sedangkan nilai $\mathrm{t}$ tabel pada taraf $\alpha=5 \%$, maka diperoleh $\mathrm{t}$ tabel 1,98. Hasil tersebut menunjukkan bahwa $t_{\text {hitung }}>\mathrm{t}_{\text {tabel }}(0,506<$ $1,98)$ dan signifikansi $(0,614>0,05)$ sehingga $\mathrm{H}_{0}$ diterima dan $\mathrm{H}_{1}$ ditolak atau dapat disimpulkan bahwa secara parsial Tangible tidak berpengaruh positif dan signifikan terhadap kepuasan mahasiswa Unilak.

\section{Hasil pengujian Pengaruh Keandalan (Reliability) terhadap Kepuasan Mahasiswa}

Berdasarkan data diperoleh nilai $\mathrm{t}$ hitung 2,373 sedangkan nilai $\mathrm{t}$ tabel pada taraf $\alpha=5 \%$, maka diperoleh $\mathrm{t}$ tabel 1,98 . Hasil tersebut menunjukkan bahwa $\mathrm{t}_{\text {hitung }}>\mathrm{t}_{\text {tabel }}$ $(2,373>1,98)$ dan signifikansi $(0,021<$ 0,05) sehingga $\mathrm{H}_{0}$ ditolak dan $\mathrm{H}_{2}$ diterima atau dapat disimpulkan bahwa secara parsial keandalan (reliability) berpengaruh positif dan signifikan terhadap kepuasan mahasiswa.

\section{Hasil pengujian Pengaruh Daya Tanggap (Responsiveness) terhadap Kepuasan Mahasiswa}

Berdasarkan data diperoleh nilai $\mathrm{t}$ hitung 1,228 sedangkan nilai $\mathrm{t}$ tabel pada taraf $\alpha=5 \%$, maka diperoleh $\mathrm{t}$ tabel 1,98 . Hasil tersebut menunjukkan bahwa $\mathrm{t}_{\text {hitung }}<\mathrm{t}$ tabel $(1,228<1,98)$ dan signifikansi $(1,224>$ 0,05) se2hingga $\mathrm{H}_{0}$ diterima dan $\mathrm{H}_{3}$ ditolak atau dapat disimpulkan bahwa secara parsial daya tanggap (responsiveness) tidak berpengaruh positif dan signifikan terhadap kepuasan mahasiswa.

\section{Hasil pengujian Pengaruh Jaminan (Assurance) terhadap Kepuasan Mahasiswa}

Berdasarkan data diperoleh nilai $\mathrm{t}$ hitung 2,248 sedangkan nilai $\mathrm{t}$ tabel pada taraf $\alpha=5 \%$, maka diperoleh $\mathrm{t}$ tabel 1,98 . Hasil tersebut menunjukkan bahwa $\mathrm{t}_{\text {hitung }}>\mathrm{t}$ tabel $(2,248>1,98)$ dan signifikansi $(0,028<$ $0,05)$ sehingga $\mathrm{H}_{0}$ ditolak dan $\mathrm{H}_{4}$ diterima atau dapat disimpulkan bahwa secara parsial Jaminan (Assurance) berpengaruh terhadap kepuasan mahasiswa. 


\section{Hasil pengujian Pengaruh Empati (Empathy) terhadap Kepuasan Mahasiswa}

Berdasarkan data diperoleh nilai $\mathrm{t}$ hitung 3,088 sedangkan nilai $\mathrm{t}_{\text {tabel }}$ pada taraf $\alpha$ $=5 \%$, maka diperoleh $\mathrm{t}$ tabel 1,98. Hasil tersebut menunjukkan bahwa $\mathrm{t}$ hitung $>\mathrm{t}$ tabel $(3,088>1,98)$ dan signifikansi $(0,003<$ 0,05) sehingga $\mathrm{H}_{0}$ ditolak dan $\mathrm{H}_{5}$ diterima atau dapat disimpulkan bahwa secara parsial empati (empathy) berpengaruh terhadap kepuasan mahasiswa.

Terlihat bahwa besarnya nilai $\mathrm{R}$ diperoleh 0,828 sehingga diketahui nilai koefisien determinasi simultan $\left(\mathrm{R}^{2}\right)$ sebesar 0,662 hal ini dapat diartikan bahwa variabel Tangible (X1), reliability (X2), responsiveness (X3), Assurance (X4), Empathy (X5) mampu menjelaskan sebesar $66,2 \%$ terhadap kepuasan nasabah (Y). Sedangkan sisanya 33,8\% dijelaskan faktorfaktor lain yang tidak termasuk pada penelitian ini.

Berdasarkan

pembahasan

sebelumnya, maka ditemukan fakta kesimpulan sebagai berikut : Bukti Fisik (Tangible) berpengaruh positif dan signifikan terhadap kepuasan mahasiswa secara simultan, namun tidak secara parsial, hal ini berarti peningkatan sarana prasarana kampus tidak serta merta meningkatkan kepuasan mahasiswa, karena mungkin mahasiswa merasa bahwa kualitas pelayanan lebih kepada kecepatan respon dan tanggapan terhadap kebutuhan mahasiswa. Keandalan (Reliability) secara simultan dan parsial berpengaruh positif dan signifikan terhadap kepuasan mahasiswa. Hasil penelitian ini mendukung hasil penelitian sebelumnya yang dilakukan Suhendra dkk (2010), yaitu Analisis Pengaruh Kualitas Pelayanan terhadap Kepuasan Nasabah Kredit pada BPR Arthaguna sejahtera, dimana keandalan (Reliability) berpengaruh positif dan signifikan terhadap kepuasan nasabah. Daya Tanggap (Responsiveness) berpengaruh positif dan signifikan terhadap kepuasan mahasiswa secara simultan namun tidak secara parsial. Hal ini berarti respon dan tanggapan dari fakultas atas kebutuhan mahasiswa tidak meningkatkan kepuasan mahasiswa atas pelayanan yang diberikan. Ini mungkin disebabkan sistem yang berbelit-belit sehingga proses administrasi berjalan lamban dalam menanggapi kebutuhan mahasiswa.

Jaminan (Assurance) berpengaruh positif dan signifikan terhadap kepuasan mahasiswa baik secara simultan maupun parsial. Hasil penelitian ini mendukung hasil penelitian sebelumnya yang dilakukan Dodik Agung (2004) yaitu, Pengaruh Kualitas Pelayanan Terhadap Kepuasan Nasabah Kredit Perorangan dan Kelompok: Studi Kasus pada BPR Bank Pasar Kabupaten Karanganyar. Menggunakan dimensi-dimensi kualitas pelayanan dimana salah satunya variabel Jaminan (assurance) secara parsial berpengaruh signifikan terhadap kepuasan mahasiswa. Empati (Empathy) berpengaruh positif dan signifikan terhadap kepuasan mahasiswa. Hasil penelitian ini mendukung hasil penelitian sebelumnya yang dilakukan Hartanto (2010), yaitu Analisis Pengaruh Kualitas Pelayanan Jasa Perbankan terhadap Kepuasan Nasabah pada PD. BPR Bank Jogja, dimana hasil pengujian membuktikan bahwa variabel Empati secara parsial memiliki pengaruh yang positif dan signifikan terhadap Kepuasan mahasiswa.

Bagi Akademisi, penelitian ini dapat memberikan kontribusi terhadap pemahaman sejauh mana pengaruh kualitas pelayanan yang terdiri dari aspek tangible, reliability, responsiveness, assurance, empathy terhadap kepuasan pelanggan yang dalam hal ini mahasiswa dalam institusi pendidikan. Bagi Unilak, melihat dampak yang dapat ditimbulkan dari aspek tangible, reliability, responsiveness, assurance, dan empathy berpengaruh terhadap kepuasan mahasiswa diharapkan Unilak untuk terus memperhatikan indikator pada kualitas pelayanan apalagi untuk aspek daya tanggap, supaya dapat lebih mengoptimalkan sistem administrasi di masing-masing fakultas sehingga kepuasan mahasiswa dapat meningkat. Bagi peneliti selanjutnya diharapkan dapat menambah faktor lain yang dapat mempengaruhi 
kepuasan nasabah . Penelitian ini hanya menggunakan metode survei yang memiliki kelemahan dan berpotensi bias. Penelitian selanjutnya diharapkan menggunakan metode wawancara agar dapat mengatasi kelemahan metode survey.

\section{SIMPULAN}

Berdasarkan uraian tersebut di atas, maka dapat disimpulkan menunjukkan bahwa tangible, reliability, responsiveness, assurance dan empathy secara simultan berpengaruh positif dan signifikan terhadap kepuasan mahasiswa. Namun secara parsial tangible dan responsiveness tidak terbukti berpengaruh signifikan terhadap kepuasan mahasiswa

\section{DAFTAR RUJUKAN}

Abdullah, T., \& Tantri, F. (2012). Bank dan Lembaga Keuangan. Raja Grafindo Persada.

Abdullah, F., Suhaimi, R., Saban, G., \& Hamali, J. (2011). Bank service quality (BSQ) index: an indicator of service performance. International Journal of Quality \& Reliability Management, 28(5), 542-555.

Amiri Aghdaie, S. F., \& Faghani, F. (2012). Mobile banking service quality and customer satisfaction (application of SERVQUAL model). International Journal of Management and Business Research, 2(4), 351-361.

Chingang Nde, D., \& Lukong, P. (2010). Using the SERVQUAL Model to assess Service Quality and Customer Satisfaction.: An Empirical Study of Grocery Stores in Umeå.

Creswell (2014) Creswell, J. W. (2014). Research design: Qualitative, quantitative, and mixed methods approaches. $4^{\text {th }}$ Edition. Sage publications.
Dibyantoro, dan Cesimariani Nani, (2012), Pengaruh Kualitas Pelayanan Jasa Terhadap Kepuasan Pelanggan Pada Cv Haspari Palembang, Jurnal Ekonomi Dan Informasi Akuntansi (Jenius)

Hartanto, Tri, 2010, Analisis Pengaruh Kualitas Pelayanan Terhadap Kepuasan Nasabah (Studi Kasus PD BPR Jogja), papers.gunadarma.ac.id

Kheng, L. L., Mahamad, O., Ramayah, T., \& Mosahab, R. (2010). The impact of service quality on customer loyalty: A study of banks in Penang, Malaysia. International journal of marketing studies, 2(2), 57-66.

Kotler, P. (2007). Marketing in the public sector. Pearson Education India.

Moenir, A. (2007). Analisis pengaruh budaya kerja terhadap kepuasan kerja dan kinerja pegawai (studi kasus pada organisasi biro ekonomi dan pembangunan sekretariat daerah provinsi jambi) (Doctoral dissertation, Institut Pertanian Bogor).

Rodrigues, L. L., Barkur, G., Varambally, K. V. M., \& Golrooy Motlagh, F. (2011). Comparison of SERVQUAL and SERVPERF metrics: an empirical study. The TQM Journal, 23(6), 629-643.

Saputra, R. L. (2014). Persepsi Mahasiswa Terhadap Pelayanan Administrasi Pegawai Biro Administrasi Akademik Dan Kemahasiswaan (BAAK) di Universitas Negeri Padang. Bahana Manajemen Pendidikan, 2(1), 564-573. 
Setyaningrum (2012) yaitu, Analisis Pengaruh Dimensi Kualitas Pelayanan Terhadap Kepuasan Pelanggan: Studi Kasus pada laundry Mayang Tlogosari Semarang

Sugiyono. 2011. Metode Penelitian Kuantitatif, Kualitatif dan $R \& D$. Bandung: CV Alfabeta.

Supadmi, N. L. (2009). Meningkatkan kepatuhan wajib pajak melalui kualitas pelayanan. Jurnal Ilmiah Akuntansi dan Bisnis, 4(2). 